REVIEW ARTICLE

\title{
Current trends and possible therapeutic options against COVID-19
}

\author{
Uzair Ahmed ${ }^{1}$, Usman Ali Ashfaq ${ }^{1}$, Saba Khaliq², Muhammad Qasim¹, Shah Jahan ${ }^{3}$, Muhammad Shareef \\ Masoud $^{1}$
}

${ }^{1}$ Department of Bioinformatics and Biotechnology, Government College University, Faisalabad, Pakistan

${ }^{2}$ Department of Physiology and Cell Biology, University of Health Sciences, Lahore, Pakistan

${ }^{3}$ Department of Immunology, University of Health Sciences, Lahore, Pakistan

\begin{abstract}
COVID-19 is a highly contagious disease, caused by SARS-CoV-2, which can be transmitted from person to person. SARS-CoV-2 has thought to be originated in bats and transmitted to humans. SARS-CoV-2 has ssRNA genome that is about $30 \mathrm{~kb}$ in length and it enters lung epithelial cells using spikes (S) by binding with Angiotensin-converting enzyme 2 (ACE-2). Till date, there is no definitive treatment available for COVID-19 and currently, only symptomatic treatments are available. There is no vaccine developed to combat COVID-19 but scientists are working on developing different types of vaccines including nucleic acid vaccines, subunit vaccines and whole virus vaccines, that are effective and safe to use. Broad spectrum antivirals like ribavirin, lopinavir, ritonavir, arbidol, favipiravir, remdesivir are being test to lessen the viral load. Recently, ivermectin (anti-parasitic drug), has been administered in vitro and showed $99.8 \%$ reduction in SARS-CoV-2 in cultured cells in 48 hours. Convalescent plasma (CP) treatments are also being used in order to treat critical cases, nevertheless, no drug has been approved yet. This review focuses on the transmission, clinical features, prevention, current treatments and future possible approaches that can be used to develop therapeutic options against COVID-19. J Microbiol Infect Dis 2019; 9(3):110-120.
\end{abstract}

Keywords: SARS-CoV-2, clinical features, therapeutic options, antivirals, vaccines

\section{INTRODUCTION}

Coronaviruses (CoVs) family is diverse, positive sense, single stranded group of RNA viruses causing various diseases, including hepatic, neurological and respiratory diseases varying in severity and can be found both in humans and animals $[1,2]$. In humans CoV has been known to cause mild respiratory infections [3] but in past two decades, Middle East respiratory syndrome CoV (MERS-CoV) and severe acute respiratory syndrome CoV (SARS-CoV-1) two novel coronaviruses emerged which caused severe disease as well as deaths in humans [4, 5]. SARS-CoV-1 death rate was about $10 \%$, which infected 8,000 people with 800 deaths reported and MERS-CoV had a death rate of $35 \%$, while infected 857 people with 334 deaths worldwide [6-8]. Now a new novel CoV known as SARS-CoV-2 has emerged that infect humans and have symptoms like shortness of breath, cough and fever which same as SARS and MERS [9, 10]. The disease caused by SARS-CoV-2 is named as COVID-19 and has become a global threat to health.

COVID-19 outbreak has infected almost 86,361 people in mainland China with about 4,655 confirmed deaths and 15,012,731 people are affected by this infectious disease globally by death toll up to 619,150 according to World Health Organization (WHO) [11] and in Pakistan there are 259,278 confirm cases and death toll is up to 5,763 according to Ministry of National Health Services Regulations and Coordination, Pakistan [12]. Social distancing and lockdowns are the basic ways to stop the spread of this contagious virus as adopted by China but in developing countries like Pakistan, it is difficult to enforce lockdown because it cripples economy and people could die from hunger.

There is no definitive vaccine or treatment available in case of COVID-19 medical staff and doctors are giving only symptomatic and

Correspondence: Dr. Muhammad Shareef Masoud, Department of Bioinformatics and Biotechnology, Government College

University, Faisalabad, Pakistan

Email: masoudshareef@gcuf.edu.pk

Received: 13 August 2020 Accepted: 31 August 2020

Copyright (C JMID / Journal of Microbiology and Infectious Diseases 2020, All rights reserved 
supportive treatments. The biggest focus nowadays is to prevent the infection from spreading further and home isolation is the first step if mild illness occurs so that its transfer can be minimized. In case of mild symptoms hydration, better nutrition and keeping the fever in check are usual principles. If the patient is tested positive of COVID-19 then use of antibiotics and antivirals should be administered with proper care. If severe condition prevails, then the oxygen should be administered and in critical cases, mechanical ventilators can be used to facilitate oxygen flow in the body [13]. Scientists are working to develop antivirals and vaccines against SARS-CoV-2. Many candidates are under clinical trials but still no vaccine or antiviral against SARS-CoV-2 has been approved yet.

In this concise review, the ways of transmission of COVID-19, its treatment options and possible vaccine options based on current and available evidence will be discussed.

\section{STRUCTURE AND TRANSMISSION OF THE VIRUS}

SARS-CoV-2 is a single stranded, positive sense RNA virus that is a member of Coronavirus family and was identified in January 2020 [14-16]. Recent studies suggest that SARS-CoV-2 was originated in bats because of its genetic sequence resembles other bat-based coronaviruses but the intermediate host between human and bats is still unknown $[17,18]$.

The main components of SARS-CoV-2 are single stranded RNA (about 30kb in size), nucleocapsid $(N)$, envelope $(E)$ and envelope spikes (S) as shown in Figure 1. Envelope spikes (S) are very important for the transmission of CoV [19] because it is crucial for receptor binding and membrane fusion [19-21]. Spike protein has 2 functional domains $S 1$ domain in charge of receptor binding and S2 domain in charge for membrane fusion [22]. The cell receptor for SARS-CoV-1 is Angiotensinconverting enzyme 2 (ACE-2) [23-25] and similar is the case of SARS-CoV-2 because of the fact that both may have the same life cycle and use ACE-2 receptor for entry into ACE-2 expressing cells [26]. Recent studies suggest that $S$ protein of SARS-CoV-2 has 10-20-fold (approx.) higher binding affinity with ACE-2 than of SARS-CoV-1 [27].
COVID-19 can be transferred from person to person through direct contact and is proved to be the method for the transfer of COVID-19 infection according to various reports [28, 29]. Human to human transfer COVID-19 occurs when an infected individual cough or sneeze via bio-aerosol production [30] or through direct contact with an infected person.

Viral infection is caused by binding of receptor which is expressed on host cells and later fusion of virus with cell membrane occurs. Various studies suggest that epithelial cells of the lungs are the primary target of viral attachment, therefore as spikes of the virus binds with the ACE-2 receptors (angiotensin-converting enzyme 2) as reported in the case of SARSCoV-1. There is striking similarity in the sequence of receptor binding domain of SARSCoV-2 spikes and SARS-CoV-1 spikes, which strongly suggests both use same ACE-2 receptors for their entry into host cells [31,32].

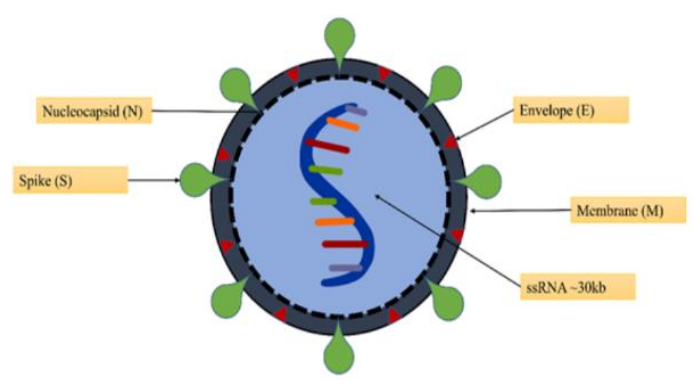

Figure 1. Structure of SARS-CoV-2.

\section{CLINICAL FEATURES}

Clinical evidence shows that COVID-19 mostly affects people ranging from age 30 to 79 years [33] and very few cases were reported in younger people having age below than 15 years. Moreover, a study indicates that half of the patients have already co-existing diseases and mostly the fatality rate was increased in patients with pre-existing ailments like cardiovascular diseases, diabetes and hypertension [33-37].

COVID-19 can be asymptomatic in some people and can cause severe respiratory failure in some cases. Fever, dyspnea and dry cough are common symptoms and headache, diarrhea, sputum production and hemoptysis are shown in rare cases, but pneumonia is developed in most cases of COVID-19 infection [33-38]. 
Symptoms arising in COVID-19 can be divided into three categories: mild symptoms, severe symptoms and critical symptoms. Mild patients had mild pneumonia, but dyspnea, abnormal respiratory frequency, low blood oxygen and pulmonary infiltrates (more than 50\%) were observed in severe patients within 48 hours. In patients with critical conditions, septic shock, respiratory failure and in worst cases, multiple organ failure occurred $[33,39]$. During the progression of disease in mild to critical stage average period to develop dyspnea from mild symptoms is 8 days and in $10-11$ days patient needs mechanical ventilation when developing into the critical stage [34]. Various symptoms developed during COVID-19 progression are shown in Figure 2.

\section{CURRENT TREATMENTS PREVENTIONS}

AND

There is no definitive vaccine or treatment available in case of COVID-19 medical staff and doctors are giving only symptomatic and supportive treatments. The biggest focus nowadays is to prevent the infection from spreading further and home isolation is the first step if mild illness occurs so that its transfer can be minimized. In case of mild symptoms hydration, better nutrition and keeping the fever in check are usual principles. If the patient is tested positive of COVID-19 then use of antibiotics and antivirals should be administered with proper care. If severe condition prevails, then the oxygen should be administered and in critical cases, mechanical ventilators can be used to facilitate oxygen flow in the body [13]. Vasoactive drugs should be administered if circulation dysfunction occurs. If renal injury occurs in patient blood purification should be administered on time. It is important to monitor brain activity of patients in order to save them from intracranial hypertension [39]. The treatments available are limited and no vaccine or antiviral have been developed against COVID-19 infection. Moreover, the antivirals like ribavirin, lopinavir, ritonavir, remdesivir, oseltamivir has also been used as they are to reduce viral loads and remdesivir showed promising effects in United States when administered to a COVID-19 patient [40, 41]. As of today, no single antiviral or vaccine has been approved for the treatment of COVID-19.
Prevention is crucial for COVID-19 because there is no treatment available currently as discussed earlier. Nonspecific symptoms, longer incubation periods, transmission from asymptomatic patient of the virus make it very difficult to take proper preventive measures. People which have COVID-19 or suspected patients of COVID-19 must be isolated from healthy persons and must wear surgical masks and wash their hands for 15-20 secs with soap. Healthcare workers have the highest risk of getting a COVID-19 infection as in 2002, SARS affected $21 \%$ of healthcare workers [42]. N95 masks, goggles and protective suits must be worn by healthcare workers while addressing COVID-19 patients. Crowded areas must be avoided and people should stay home to avoid unnecessary contact to limit the spread of COVID-19. Hands should be washed every 30 mins or sanitized using an alcohol-based hand sanitizer and surfaces should be cleaned regularly. Touching eyes, nose or face must be avoided. Schematic illustration of preventive measures against COVID-19 is shown in Figure 3. In order to combat this epidemic, we must follow these preventive measures to ensure our safety.

\section{POTENTIAL THERAPEUTIC APPROACHES BEING USED AGAINST COVID-19}

\section{Inhibition of SARS-COV-2 Entry or Fusion}

As discussed above, SARS-CoV-2 enters the host cells using its spikes (S) which binds to ACE-2 receptors of a host cell to gain entry [15, 43] and ACE-2 receptors are recognized more efficiently by SARS-CoV-2 [31]. Therefore, to inhibit the entry of SARS-CoV-2 into host cells, receptor binding domain (RBD) of $S$ protein may be a potential target for neutralizing antibodies. In a study, the neutralizing antibodies of SARSCoV-1 showed potent binding to RBD of SARSCoV-2 due to striking similarities in their protein structure [44]. But, SARS-CoV-2 antibody epitopes are proven to show extraordinary variations as compared to SARS-CoV-1 therefore, there is an imminent need to synthesize new monoclonal antibodies to inhibit RBD of SARS-CoV-2 [45]. But in the case of SARS-CoV-2, ACE-2 is not only receptor for entry into host cells, but cellular serine protease (TMPRSS2) is also critical for entry of viruses and use of TMPRSS2 inhibitor camostat mesylate was found out to reduce lung infection 
and can be used in future for COVID-19 treatment [46]. Moreover, cell membrane fusion of the virus is also done with the involvement of heptad repeat 1 and heptad repeat 2 (HR1 and HR2) present on SARS-CoV-2 and it was shown in a study that HR2 derived peptides displayed inhibition in the fusion of virus which can be potentially used in the COVID-19 infections [47].
Researchers also identified that $\mathrm{pH}$ and receptor dependent endocytosis also plays important role in the entry of Coronaviruses [48, 49] and this approach can also be used in the case of SARSCoV-2 [50]. Figure 4 show the infection cycle of SARS-CoV-2 and the potential targets for drug/vaccine development.

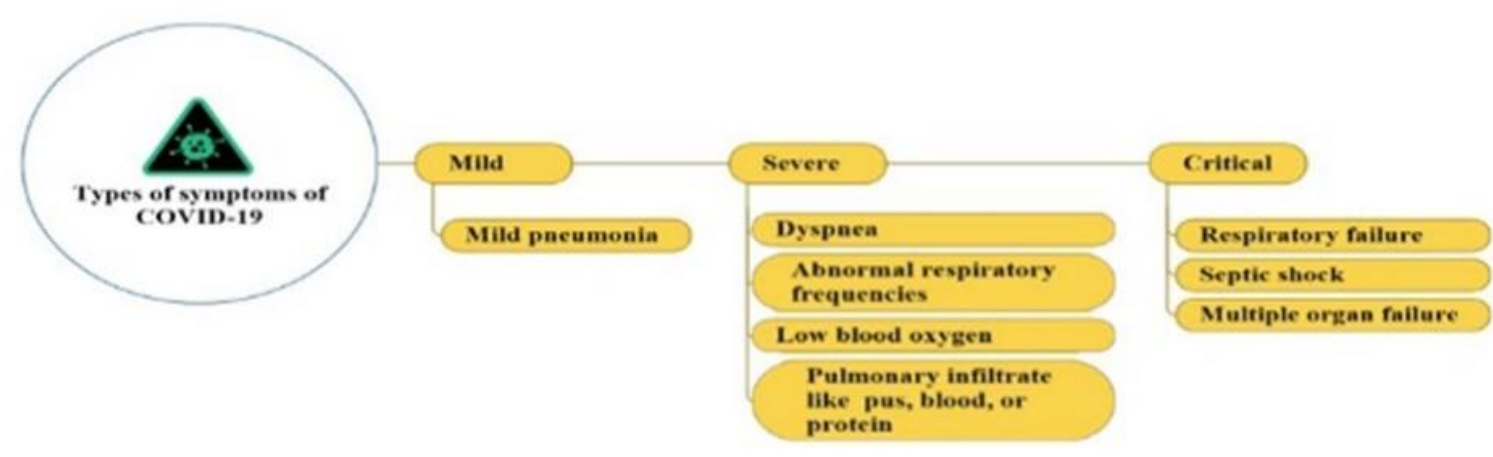

Figure 2. Clinical symptoms of COVID-19.

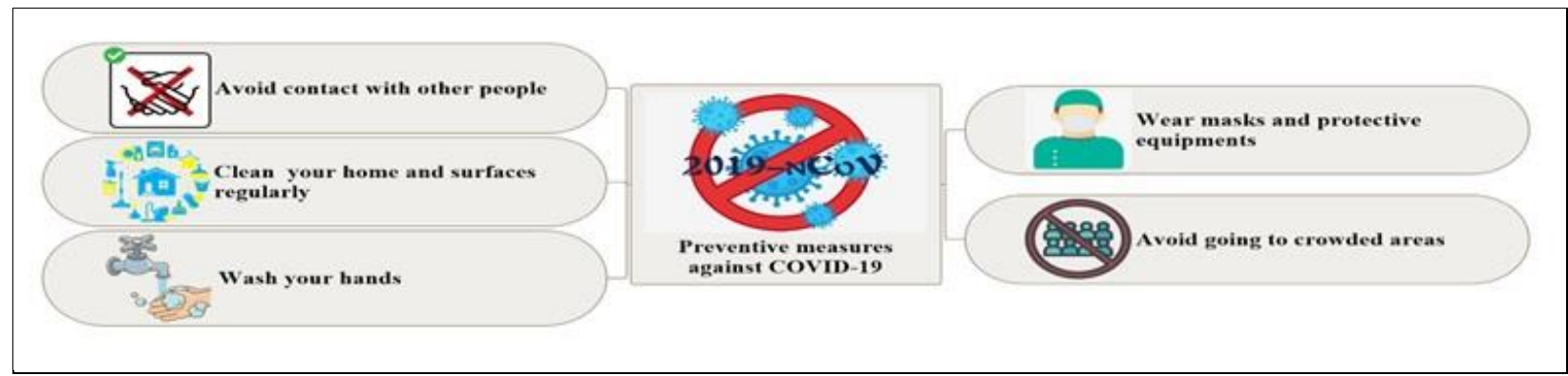

Figure 3. Preventive measures against COVID-19 epidemic.

In recent study use of chloroquine phosphate, an antimalarial drug, showed a tremendous potential against SARS-CoV-2 and in various clinical trials chloroquine phosphate was administered to more than 100 COVID-19 patients that resulted in reduction of pneumonia as compared to control group patients $[51,52]$ In another study hydroxychloroquine showed more inhibition potential than chloroquine phosphate for the COVID-19 [53]. Chloroquine can inhibit virus entry via 2 potential mechanisms: a) They might block the production of inflammatory cytokines like IL6, whose abnormal production during COVID-19 leads to acute respiratory syndrome [54]; b) It accumulates in endosomes thus raised the $\mathrm{pH}$ of endosome which helps in can interfere with entry or fusion of virus [55, 56]. Nevertheless, there is still a dire need to test these potential approaches in the lab as well as in clinical trials to develop treatment for COVID-19 infection.

\section{Disruption of Replication of SARS-CoV-2}

To fight against RNA viruses, a great number of antivirals has been developed which disrupts viral replication via inhibition of viral polymerases. As discussed above, antivirals like ribavirin, lopinavir, ritonavir, arbidol, favipiravir, remdesivir are being employed against SARSCoV-2 and remdesivir showed the most promising results against COVID-19 [51, 57] which was also used through intravenous injection in United States, thus improving the condition of the COVID-19 patient [40]. It is a monophosphoramidate prodrug of an adenosine analog which causes RNA synthesis arrest by incorporation into newly synthesized viral RNA with the help of RNA-dependent RNA 
polymerases [58]. Ribavirin and favipiravir are monophosphoramidate prodrugs of guanine analogues are being used for other RNA viruses treatments but there is still no data supporting their antiviral effects in patients with COVID-19 [59]. Protease inhibitors like ritonavir and lopinavir targets coronavirus proteinase 3 CLpro (3C-like protease), which is responsible for processing of translation products of RNA viruses, can be effectively used against SARSCoV-2[60]. Tegobuvir, prulifloxacin, nelfinavir and bictegravir are small molecules that showed reasonable bindings to viral protease in result inhibiting it and are screened using highthroughput screening methods in clinical laboratories [61]. A recent study, showed that ivermectin, an FDA approved drug having antiparasitic activity, has shown promising results in reduction of SARS-CoV-2. In the experiment, $5 \mu \mathrm{M}$ of ivermectin was administered in Vero/hSLAM cells infected by SARS-CoV-2 and the viral RNA was found out to be reduced by $99.8 \%$, in vitro [62].

Another approach that can be used to inhibit SARS-CoV-2 replication is to use the novel CRISPR/Cas13 system to cleave RNA genome of the virus which can be delivered to the infected lung via adeno associated virus vectors. It contains guide RNAs, containing spacer sequences explicitly complementary to the virus RNA genome and Cas13d protein [63].

\section{Inflammatory Response Suppression}

An optimal level of cytokines is essential for immune system to work properly, but it is reported that during COVID-19 infection the concentration of cytokines was increased in critical patients as compared to mild patients which shows higher cytokine concentrations are directly linked to disease severity [34]. Therefore, inhibition of elevated inflammatory response can be a potential approach to decrease the severity of COVID-19 and corticosteroid can be used to alleviate the inflammatory response caused by abnormal concentrations of cytokines [57]. There is no evidence that corticosteroid administration improved the inflammatory response in the case of SARS and MERS so, currently it is recommended by National Health Commission, China (NHC) not to use corticosteroids to treat COVID-19 [64]. A recent study showed the probable benefits of corticosteroids if administered in low dosage in person with COVID-19 [65] but more clinical trial and studies are needed to prove the effectiveness of corticosteroids against COVID-19.

During SARS-CoV-2 infection, CD14+, CD16+, monocytes were activated along with high expression of IL6 which was induced by activation of GM-CSF (Granulocyte-macrophage colony-stimulating factor) and other inflammatory cytokines at cellular level [66]. Thus, IL6 and GM-CSF could be a potential target to reduce overexpressed inflammatory response in COVID-19 patients. Activation of FC receptors (FcR) mediated inflammatory response could contribute to the abnormal inflammatory response in SARS-CoV-2 infection thus, FcR inhibitors can be a potential option to reduce inflammatory responses induced by SARS-CoV-2 infection [67].

\section{Treatment with Convalescent Plasma (CP)}

Convalescent plasma (CP) is the plasma taken from a patient that survived any infection by developing antibody-mediated immunity against that specific pathogen. When there is no cure or treatment available for a disease, CP can be used effectively to help lessen the severity of disease. Regardless of the fact that efficiency of CP therapy is proved by many studies, good random trials and clinical studies are needed to properly use CP treatment as a treatment option [68].

During the novel corona virus outbreaks convalescent plasma (CP) can be used as a treatment option if there is no proper treatment available [69] which is done by taking CP from person recovered from COVID-19 by developing immunity against viruses [70]. In a recovered person, specific antibody has been developed against infection, which give CP therapeutic attributes [68] but clinical trials and studies must be done to evaluate the efficiency of CP treatment. Patients in critical condition should be administered with CP of the patients recovered form COVID-19 [71]. However, many trials are being conducted in order to test the safety and efficiency of CP for treatment of COVID-19 patients.

\section{Vaccines Development}

In the current global epidemic of COVID-19, the most efficient way is to vaccinate people in order 
to prevent the spread of disease [72]. Currently, many teams are working hard to develop a vaccine against COVID-19 and $S$ protein is a potential target for development of vaccines. Recently the cryo-EM structure of SARS-CoV-2 $S$ trimer has been published which will help in the timely development of new vaccine [27]. In other research, human and viral proteomes were compared and found 107 human peptides that were embedded in the S protein of SARS-CoV-2 that paved way toward the development of a vaccine by yielding 66 candidate epitopes from $S$ protein pentapeptides [73]. Currently, more than 15 vaccine candidates are being developed for COVID-19 as shown in Table 1. These include DNA/RNA based vaccines, adenoviral vector-based vaccines, inactivated vaccines etc. [26, 74]. Johnson \& Johnson and Codagenix/Serum Institute of India are working on whole virus vaccines, Novavax, University of Queensland/CEPI, Clover Biopharmaceuticals are working on subunit vaccines and CureVac/CEPI, Inovio/Beijing Advaccine Biotechnology Co./CEPI, Moderna/NIH/CEPI are working of nucleic acid-based vaccine. There is still too little data on clinical trial of vaccines at this time and vaccines must be made safe and accessible for the whole world to fight this epidemic.

\section{Whole Virus Vaccines}

Inactive whole virus or live-attenuated virus can be used as vaccine option and has been used since the discovery of vaccination. Janssen (Johnson \& Johnson) has been working to develop adenovirus-vectored vaccine [75] and Codagenix has been working on live-attenuated vaccine by using codon deoptimization technology [76]. Whole virus vaccines exhibit major advantages like their ability to stimulate toll-like receptors (TLRs) and their intrinsic immunogenicity but live virus vaccines require rigorous testing to ensure their safety. Moreover, in case of coronaviruses, administration of killed or live virus can increase the infection of that coronavirus [84]. So, clinicals trials and research should be done to test the safety and efficiency of whole virus vaccines prior to their use.

\section{Subunit vaccines}

A vaccine that contains subunits of virus that helps in stimulating protective immune response for a long period of time is called subunit vaccine
[85]. In the case of coronaviruses $S$ protein is used as primary target of subunits vaccines to prevent its docking to ACE-2 by provoking immune response against $S$ protein [84]. The University of Queensland is developing proteinbased vaccine using Molecular Clamp platform [79], Clover Biopharmaceuticals is developing Strimer recombinant protein using Trimer-Tag technology [80] and Novavax are trying to develop subunit vaccine using recombinant nanoparticle technology [78]. These subunit vaccines may prove to be effective in the activating the hosts immune response to develop antibodies that inhibits the binding of $S$ protein of SARS-CoV-2 to ACE-2, thus inhibiting the entry of virus into lungs cell.

\section{Nucleic Acid Vaccines}

A vaccine in which DNA or RNA construct is made using viral gene and injected into host cell thus developing innate immunity against that specific viral protein are called nucleic acidbased vaccines [86]. CureVac [81] and Moderna [83] are working of mRNA-based vaccines against SARS-CoV-2, whereas DNA based vaccine is in development by Inovio Pharmaceuticals [82]. The concept of nucleic acid vaccine was initiated in 1993 in mice against influenza but it hasn't shown promising results in humans [26]. Nowadays nucleic acid vaccine has developed further but more studies and clinical trials are needed to ensure the safety and efficiency of nucleic acid-based vaccines.

\section{Vaccines in clinical trials}

As of now many vaccine candidates have entered phase 3 of clinical trials and showing promising results in developing antibodies against SARS-CoV-2.SINOPHARM and SINOVAC have entered phase 3 of clinical trials, after the administration of vaccine neutralizing antibodies were observed in phase 1 and 2 clinical trials without any adverse side effects $[87,88]$. The vaccines by University of Oxford, Moderna and CanSino Biologics have completed phase 2 clinical trials and observed the production of neutralizing antibodies within 14 days of administration with no side effects $[77,89]$. The vaccine from CanSino Biologics developed humoral immunity and reduced the symptoms of COVID drastically [90]. 


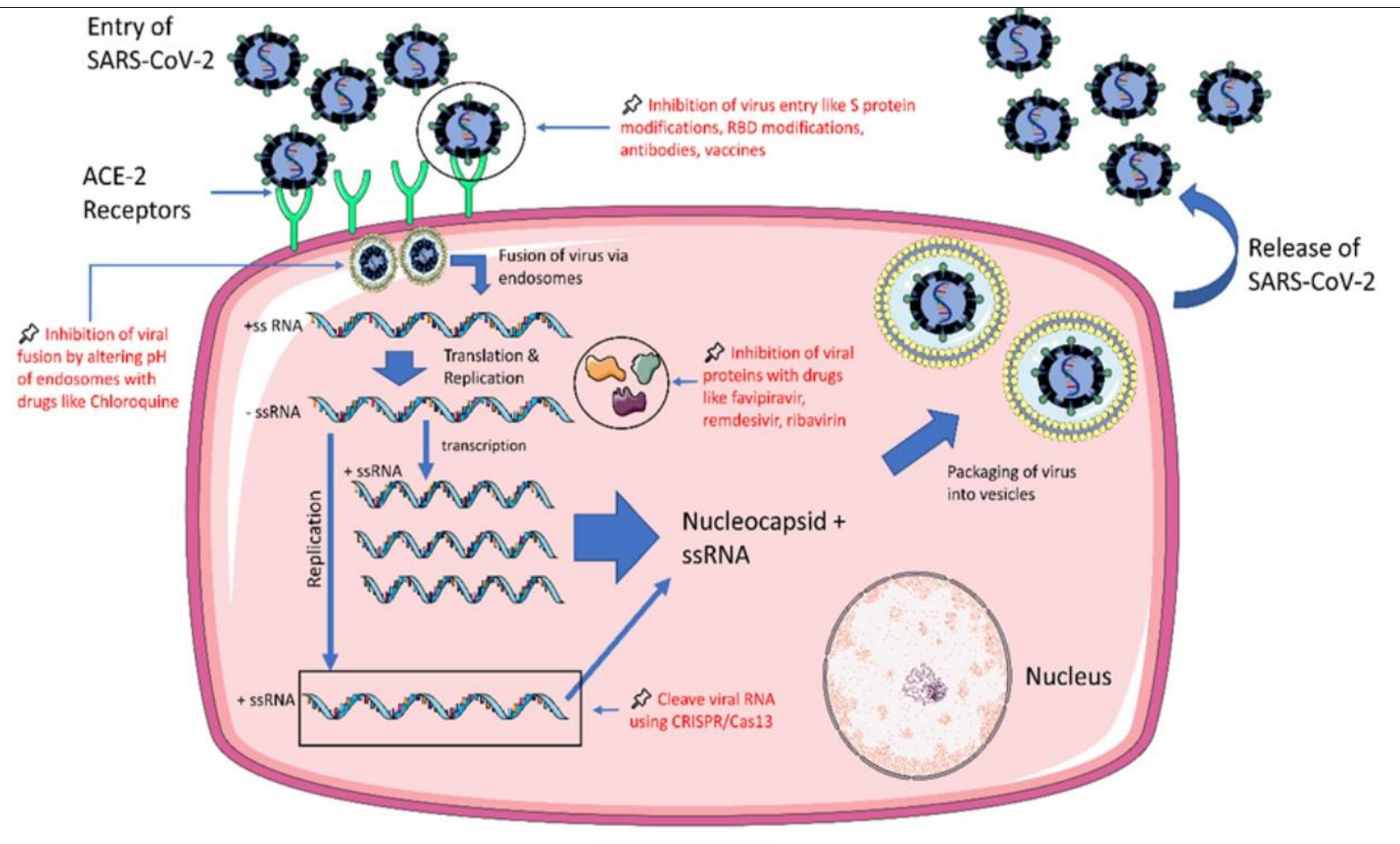

Figure 4. SARS-CoV-2 infection cycle and potential therapeutic targets for drug/vaccine development (highlighted in red color).

Table 1. Different vaccines being developed against SARS-CoV-2.

\begin{tabular}{lccc}
\hline Type of Vaccine & Vaccine candidates & Companies Working on Vaccine & References \\
\hline Whole virus & Adenovirus-vectored vaccine & Janssen (Johnson \& Johnson) & 75 \\
vaccines & Live-attenuated vaccine & Codagenix/Serum Institute of India & 76 \\
Subunit & Adenovirus-vectored vaccine & University of Oxford & 77 \\
vaccines & Recombinant nanoparticle technology & Novavax & 78 \\
& Protein-based vaccine using Molecular & University of Queensland/CEPI & 79 \\
& Clamp platform & & \\
& S-trimer recombinant protein using & Clover Biopharmaceuticals & 80 \\
Nucleic acid & Trimer-Tag technology & & \\
vaccines & mRNA vaccine & CureVac/CEPI & 81 \\
& DNA vaccine & Inovio/Beijing Advaccine & 82 \\
& mRNA vaccine & Biotechnology Co./CEPI & \\
\hline
\end{tabular}

\section{CONCLUSION AND FUTURE DIRECTIONS}

The SARS-CoV-2 emerged in Wuhan, China and has been declared as a global pandemic by the WHO. It is of zoonotic origin and thought to originate and mutated from bats. SARS-CoV-2 has a single stranded RNA genome and enters host cells through ACE receptors using spike protein. Although SARS-CoV-2 has much similarities with the SARS-CoV-1 but still no treatments or vaccine has been developed against COVID-19 infection. Antivirals with broad spectrum antibiotics are being used to treat COVID-19 in order to find a cure for it. Remdesivir has found out to be effective against SARS-CoV-2 during in vitro studies. Many companies are working on different type of vaccines, but not a single one is approved for use till date. Therefore, prevention is the only effective measure against this virus so far and 
there is a dire need to develop an effective vaccine and other treatment options to deal with COVID-19.

\section{ACKNOWLEDGMENTS}

Declaration of Conflicting Interests: The authors declare that they have no conflict of interest.

\section{Funding: Not applicable \\ REFERENCES}

1. Zumla A, Chan JFW, Azhar El, et al. Coronaviruses-drug discovery and therapeutic options. Nature Reviews Drug Discovery 2016; 15: 327-347.

2. Chan JFW, Lau SKP, Woo PCY. The emerging novel Middle East respiratory syndrome coronavirus: The 'knowns' and 'unknowns'. Journal of the Formosan Medical Association 2013; 112: 372-381.

3. Channappanavar R, Zhao J, Perlman S. T cellmediated immune response to respiratory coronaviruses. Immunologic Research 2014; 59: 118128.

4. Chan JFW, Lau SKP, To KKW, et al. Middle East Respiratory syndrome coronavirus: Another zoonotic betacoronavirus causing SARS-like disease. Clin Microbiol Rev 2015; 28: 465-522.

5. Cheng VCC, Lau SKP, Woo PCY, et al. Severe acute respiratory syndrome coronavirus as an agent of emerging and reemerging infection. Clinical Microbiology Reviews 2007; 20: 660-694.

6. Gralinski LE, Baric RS. Molecular pathology of emerging coronavirus infections. J Pathol 2015; 235: 185-195.

7. Drosten C, Günther S, Preiser W, et al. Identification of a Novel Coronavirus in Patients with Severe Acute Respiratory Syndrome. N Engl J Med 2003; 348: 1967-1976.

8. Gretebeck LM, Subbarao K. Animal models for SARS and MERS coronaviruses. Current Opinion in Virology 2015; 13: 123-129.

9. Liu J, Zheng X, Tong $Q$, et al. Overlapping and discrete aspects of the pathology and pathogenesis of the emerging human pathogenic coronaviruses SARS-CoV, MERS-CoV, and 2019-nCoV. J Med Virol 2020; 92: 491-494.

10. He F, Deng Y, Li W. Coronavirus Disease 2019 (COVID-19): What we know? J Med Virol 2020; 1-7.

11. WHO | World Health Organization, https://www.who.int/ (2020, accessed 2 April 2020).

12. COVID-19 Health Advisory Platform by Ministry of National Health Services Regulations and Coordination, http://covid.gov.pk/ (2020, accessed 5 April 2020).
13. Singhal T. A Review of Coronavirus Disease-2019 (COVID-19). Indian J Pediatr 2020; 87: 281-286.

14. Zhu N, Zhang D, Wang W, et al. A novel coronavirus from patients with pneumonia in China, 2019. N Engl J Med 2020; 382: 727-733.

15. Zhou $P$, Yang $X$ Lou, Wang $X G$, et al. $A$ pneumonia outbreak associated with a new coronavirus of probable bat origin. Nature 2020; 579: 270-273.

16. Lu R, Zhao X, Li J, et al. Genomic characterisation and epidemiology of 2019 novel coronavirus: implications for virus origins and receptor binding. Lancet 2020; 395: 565-574.

17. Li X, Zai J, Zhao Q, et al. Evolutionary history, potential intermediate animal host, and cross-species analyses of SARS-CoV-2. J Med Virol 2020; jmv.25731.

18. Zhou P, Yang X-L, Wang X-G, et al. Discovery of a novel coronavirus associated with the recent pneumonia outbreak in humans and its potential bat origin. Nature 2020; 2020.01.22.914952.

19. Du L, He Y, Zhou Y, et al. The spike protein of SARS-CoV - A target for vaccine and therapeutic development. Nature Reviews Microbiology 2009; 7: 226-236.

20. Lu G, Wang Q, Gao GF. Bat-to-human: Spike features determining 'host jump' of coronaviruses SARS-CoV, MERS-CoV, and beyond. Trends in Microbiology 2015; 23: 468-478.

21. Wang Q, Wong G, Lu G, et al. MERS-CoV spike protein: Targets for vaccines and therapeutics. Antiviral Research 2016; 133: 165-177.

22. He Y, Zhou Y, Liu S, et al. Receptor-binding domain of SARS-CoV spike protein induces highly potent neutralizing antibodies: Implication for developing subunit vaccine. Biochem Biophys Res Commun 2004; 324: 773-781.

23. Kuba K, Imai $Y$, Rao $S$, et al. A crucial role of angiotensin converting enzyme 2 (ACE2) in SARS coronavirus-induced lung injury. Nat Med 2005; 11 : 875-879.

24. Oudit GY, Kassiri Z, Jiang C, et al. SARScoronavirus modulation of myocardial ACE2 expression and inflammation in patients with SARS. Eur J Clin Invest 2009; 39: 618-625.

25. Li W, Moore MJ, Vasllieva N, et al. Angiotensinconverting enzyme 2 is a functional receptor for the SARS coronavirus. Nature 2003; 426: 450-454.

26. Chen WH, Strych U, Hotez PJ, et al. The SARSCoV-2 Vaccine Pipeline: an Overview. Curr Trop Med Reports 2020; 1-4.

27. Wrapp D, Wang N, Corbett KS, et al. Cryo-EM structure of the 2019-nCoV spike in the prefusion conformation. Science (80- ) 2020; 367: 1260-1263. 
28. Graham Carlos W, Dela Cruz CS, Cao B, et al. Novel Wuhan (2019-NCoV) coronavirus. American Journal of Respiratory and Critical Care Medicine 2020; 201: P7-P8.

29. Wu P, Hao X, Lau EHY, et al. Real-time tentative assessment of the epidemiological characteristics of novel coronavirus infections in Wuhan, China, as at 22 January 2020. Euro Surveill; 25. Epub ahead of print 1 January 2020. DOI: 10.2807/15607917.ES.2020.25.3.2000044.

30. Wang J, Du G. COVID-19 may transmit through aerosol. Irish J Med Sci (1971 -) 2020; 1-2.

31. Wan Y, Shang J, Graham R, et al. Receptor recognition by novel coronavirus from Wuhan: An analysis based on decade-long structural studies of SARS. J Virol; 94. Epub ahead of print 29 January 2020. DOI: 10.1128/jvi.00127-20.

32. Jaimes JA, Millet JK, Stout AE, et al. A Tale of Two Viruses: The Distinct Spike Glycoproteins of Feline Coronaviruses. Viruses 2020; 12: 83.

33. Wu Z, McGoogan JM. Characteristics of and Important Lessons from the Coronavirus Disease 2019 (COVID-19) Outbreak in China: Summary of a Report of 72314 Cases from the Chinese Center for Disease Control and Prevention. JAMA - J Am Med Assoc. Epub ahead of print 2020. DOI: 10.1001/jama.2020.2648

34. Huang $\mathrm{C}$, Wang $\mathrm{Y}$, Li X, et al. Clinical features of patients infected with 2019 novel coronavirus in Wuhan, China. Lancet 2020; 395: 497-506.

35. Chen N, Zhou M, Dong X, et al. Epidemiological and clinical characteristics of 99 cases of 2019 novel coronavirus pneumonia in Wuhan, China: a descriptive study. Lancet 2020; 395: 507-513.

36. Chan JFW, Yuan S, Kok KH, et al. A familial cluster of pneumonia associated with the 2019 novel coronavirus indicating person-to-person transmission: a study of a family cluster. Lancet 2020; 395: 514 523.

37. Li Q, Guan X, Wu P, et al. Early Transmission Dynamics in Wuhan, China, of Novel CoronavirusInfected Pneumonia. N Engl J Med. Epub ahead of print 29 January 2020. DOI: 10.1056/nejmoa2001316.

38. Wang D, Hu B, Hu C, et al. Clinical Characteristics of 138 Hospitalized Patients with 2019 Novel Coronavirus-Infected Pneumonia in Wuhan, China. JAMA - J Am Med Assoc 2020; 323: 1061-1069.

39. Chen ZM, Fu JF, Shu Q, et al. Diagnosis and treatment recommendations for pediatric respiratory infection caused by the 2019 novel coronavirus. World Journal of Pediatrics 2020; 1-7.

40. Holshue ML, DeBolt C, Lindquist S, et al. First Case of 2019 Novel Coronavirus in the United States. N Engl J Med 2020; 382: 929-936.

41. Zhang C, Huang S, Zheng F, et al. Controversial treatments: an updated understanding of the
Coronavirus Disease 2019. J Med Virol 2020; n/a: 02

42. Chang D, Xu H, Rebaza A, et al. Protecting health-care workers from subclinical coronavirus infection. The Lancet Respiratory Medicine 2020; 8: e13.

43. Walls AC, Park Y-J, Tortorici MA, et al. Structure, Function, and Antigenicity of the SARS-CoV-2 Spike Glycoprotein. Cell. Epub ahead of print 6 March 2020. DOI: 10.1016/j.cell.2020.02.058.

44. Tian X, Li C, Huang A, et al. Potent binding of 2019 novel coronavirus spike protein by a SARS coronavirus-specific human monoclonal antibody. Emerging Microbes and Infections 2020; 9: 382-385.

45. Zheng M, Song L. Novel antibody epitopes dominate the antigenicity of spike glycoprotein in SARS-CoV-2 compared to SARS-CoV. Cell Mol Immunol 2020; 1-3.

46. Hoffmann M, Kleine-Weber H, Schroeder S, et al. SARS-CoV-2 Cell Entry Depends on ACE2 and TMPRSS2 and Is Blocked by a Clinically Proven Protease Inhibitor. Cell. Epub ahead of print 5 March 2020. DOI: 10.1016/j.cell.2020.02.052.

47. Xia S, Zhu Y, Liu M, et al. Fusion mechanism of 2019-nCoV and fusion inhibitors targeting HR1 domain in spike protein. Cellular and Molecular Immunology 2020; 1-3.

48. Wang $\mathrm{H}$, Yang $\mathrm{P}$, Liu $\mathrm{K}$, et al. SARS coronavirus entry into host cells through a novel clathrin- and caveolae-independent endocytic pathway. Cell Res 2008; 18: 290-301.

49. Inoue Y, Tanaka N, Tanaka Y, et al. ClathrinDependent Entry of Severe Acute Respiratory Syndrome Coronavirus into Target Cells Expressing ACE2 with the Cytoplasmic Tail Deleted. J Virol 2007; 81: 8722-8729.

50. Li H, Zhou Y, Zhang M, et al. Updated approaches against SARS-CoV-2. Antimicrob Agents Chemother. Epub ahead of print 2020. DOI: 10.1128/AAC.0048320.

51. Wang M, Cao R, Zhang L, et al. Remdesivir and chloroquine effectively inhibit the recently emerged novel coronavirus (2019-nCoV) in vitro. Cell Research 2020; 30: 269-271.

52. Gao J, Tian Z, Yang X. Breakthrough: Chloroquine phosphate has shown apparent efficacy in treatment of COVID-19 associated pneumonia in clinical studies. Biosci Trends 2020; 14: 72-73.

53. Yao X, Ye F, Zhang M, et al. In Vitro Antiviral Activity and Projection of Optimized Dosing Design of Hydroxychloroquine for the Treatment of Severe Acute Respiratory Syndrome Coronavirus 2 (SARSCoV-2). Clin Infect Dis. Epub ahead of print 2020. DOI: $10.1093 / \mathrm{cid} / \mathrm{ciaa237/5801998.}$

54. Savarino A, Boelaert JR, Cassone A, et al. Effects of chloroquine on viral infections: An old drug against 
today's diseases? Lancet Infectious Diseases 2003; 3: 722-727.

55. Vincent MJ, Bergeron E, Benjannet $S$, et al. Chloroquine is a potent inhibitor of SARS coronavirus infection and spread. Virol J 2005; 2: 1-10.

56. Golden EB, Cho HY, Hofman FM, et al. Quinolinebased antimalarial drugs: A novel class of autophagy inhibitors. Neurosurg Focus; 38. Epub ahead of print 2015. DOI: 10.3171/2014.12.FOCUS14748.

57. Martinez MA. Compounds with therapeutic potential against novel respiratory 2019 coronavirus. Antimicrob Agents Chemother 2020; 1-18.

58. Gordon CJ, Tchesnokov EP, Feng JY, et al. The antiviral compound remdesivir potently inhibits RNAdependent RNA polymerase from Middle East respiratory syndrome coronavirus. J Biol Chem 2020; jbc.AC120.013056.

59. Li G, De Clercq E. Therapeutic options for the 2019 novel coronavirus (2019-nCoV). Nature reviews. Drug discovery 2020; 19: 149-150.

60. Morse JS, Lalonde T, Xu S, et al. Learning from the Past: Possible Urgent Prevention and Treatment Options for Severe Acute Respiratory Infections Caused by 2019-nCoV. ChemBioChem 2020; 21: 730-738.

61. Li Y, Zhang J, Wang N, et al. Therapeutic Drugs Targeting 2019-nCoV Main Protease by HighThroughput Screening. bioRxiv 2020; 2020.01.28.922922.

62. Caly L, Druce JD, Catton MG, et al. The FDAapproved Drug Ivermectin inhibits the replication of SARS-CoV-2 in vitro. Antiviral Res 2020; 104787.

63. Nguyen TM, Zhang Y, Pandolfi PP. Virus against virus: a potential treatment for 2019-nCov (SARSCoV-2) and other RNA viruses. Cell Research 2020; 30: $189-190$.

64. Russell CD, Millar JE, Baillie JK. Clinical evidence does not support corticosteroid treatment for 2019nCoV lung injury. The Lancet 2020; 395: 473-475.

65. Zhou W, Liu Y, Tian D, et al. Potential benefits of precise corticosteroids therapy for severe 2019-nCoV pneumonia. Signal Transduction and Targeted Therapy 2020; 5: 1-3.

66. Zhou Y, Fu B, Zheng X, et al. Aberrant pathogenic GM-CSF + T cells and inflammatory CD14+CD16+ monocytes in severe pulmonary syndrome patients of a new coronavirus. bioRxiv 2020; 2020.02.12.945576.

67. Fu Y, Cheng Y, Wu Y. Understanding SARS-CoV2-Mediated Inflammatory Responses: From Mechanisms to Potential Therapeutic Tools. Virologica Sinica 2020; 1-6.

68. Marano G, Vaglio S, Pupella S, et al. Convalescent plasma: New evidence for an old therapeutic tool? Blood Transfusion 2016; 14: 152157.
69. Chen L, Xiong J, Bao L, et al. Convalescent plasma as a potential therapy for COVID-19. Lancet Infect Dis 2020; 20: 398-400.

70. Garraud O, Heshmati F, Pozzetto B, et al. Plasma therapy against infectious pathogens, as of yesterday, today and tomorrow. Transfus Clin Biol 2016; 23: 3944.

71. National Health Commission of the PRC, http://en.nhc.gov.cn/ (2020, accessed 3 April 2020).

72. Lu S. Timely development of vaccines against SARS-CoV-2. Emerging Microbes and Infections 2020; 9: 542-544.

73. Lucchese G. Epitopes for a 2019-nCoV vaccine. Cell Mol Immunol 2020; 1-2.

74. Pang J, Wang MX, Ang IYH, et al. Potential Rapid Diagnostics, Vaccine and Therapeutics for 2019 Novel Coronavirus (2019-nCoV): A Systematic Review. J Clin Med 2020; 9: 623.

75. Johnson J\&. Novel Coronavirus, SARS-CoV-2 | Johnson \& Johnson, https://www.jnj.com/coronavirus (2020, accessed 3 April 2020).

76. Codagenix. Codagenix and Serum Institute of India Initiate Co-Development of a Scalable, LiveAttenuated Vaccine Against the 2019 Novel Coronavirus, COVID-19 | BioSpace, https://www.biospace.com/article/releases/codagenixand-serum-institute-of-india-initiate-co-developmentof-a-scalable-live-attenuated-vaccine-against-the2019-novel-coronavirus-covid-19/ (2020, accessed 3 April 2020).

77. Oxford $U$ of. Landmark partnership announced for development of COVID-19 vaccine | University of Oxford, http://www.ox.ac.uk/news/2020-04-30landmark-partnership-announced-development-covid19-vaccine\# (2020, accessed 30 April 2020).

78. Coronavirus: Vir Biotechnology and Novavax announce vaccine plans, https://www.pharmaceuticaltechnology.com/news/coronavirus-vir-biotechnologynovavax-vaccine/ (2020, accessed 3 April 2020).

79. Hennessy J. Australia's Been Asked to Make a Coronavirus Vaccine at 'Unprecedented Speed', https://www.sciencealert.com/australian-scientistsasked-to-make-coronavirus-vaccine-atunprecedented-speed (2020, accessed 3 April 2020).

80. Biopharmaceuticals C. Clover Initiates Development of Recombinant Subunit-Trimer Vaccine for Wuhan Coronavirus (2019-nCoV) | Vaccines | News Channels, https://pipelinereview.com/index.php/2020012873644/ Vaccines/Clover-Initiates-Development-of-

Recombinant-Subunit-Trimer-Vaccine-for-WuhanCoronavirus-2019-nCoV.html (2020, accessed 3 April 2020).

81. Smith J. CureVac Bids to Develop First mRNA Coronavirus Vaccine Let' $s$ Continue the Conversation, 
https://www.labiotech.eu/medical/curevac-

coronavirus-outbreak-cepi/ (2020, accessed 3 April 2020).

82. Pharmaceuticals I. Inovio Pharmaceuticals, Inc. Inovio Collaborating with Beijing Advaccine To Advance INO-4800 Vaccine Against New Coronavirus In China, http://ir.inovio.com/news-andmedia/news/press-release-details/2020/Inovio-

Collaborating-With-Beijing-Advaccine-To-Advance-

INO-4800-Vaccine-Against-New-Coronavirus-In-

China/default.aspx (2020, accessed 3 April 2020).

83. Park A. Inside the Company That's Developing the First Coronavirus Vaccine | Time, https://time.com/5775784/coronavirus-vaccineresearch/ (2020, accessed 3 April 2020).

84. Jiang S, Bottazzi ME, Du L, et al. Roadmap to developing a recombinant coronavirus $S$ protein receptor-binding domain vaccine for severe acute respiratory syndrome. Expert Rev Vaccines 2012; 11: 1405-1413.

85. Skwarczynski M, Toth I. Introduction. Micro- and Nanotechnology in Vaccine Development 2017; xviixviii.

86. Stanberry LR. Genital and Perinatal Herpes Simplex Virus Infections. In: Sexually Transmitted Diseases. Elsevier Ltd, 2013, pp. 273-313.

87. SINOPHARM,

http://www.sinopharm.com/1156.html

(2020, accessed 24 July 2020).

88. SINOVAC - Supply Vaccines to Eliminate Human Diseases, http://www.sinovac.com/ (2020, accessed 24 July 2020).

89. Moderna, Inc. Home, https://www.modernatx.com/ (2020, accessed 24 July 2020).

90. CanSino Biologics Inc, http://www.cansinotech.com/ (2020, accessed 24 July 2020). 